\title{
EDITORIAL
}

\section{In This Issue: Prescribing Drugs: What Do Patients and Pharmaceutical Companies Really Want?}

\author{
Kurt C. Stange, $M D, P b D$, Editor \\ Ann Fam Med 2006;4:482-483. DOI: 10.1370/afm.653.
}

$\mathrm{I}$ n this issue we present research, methodology, and commentary with important implications for policy as well as practice. Five of these studies are from Europe, providing a clinical focus that is underrepresented in US primary care research and a policy relevance that benefits from system differences. Four studies use qualitative methods to discover phenomena from the perspective of participants on both sides of the health care experience. Four studies use epidemiological methods to count and assess statistical associations among variables that can be measured. One study sequentially uses qualitative and quantitative methods to develop a new measure of continuity of care that is grounded in the experience of diabetic patients and validated against psychometric criteria and other quantitatively measured variables. ${ }^{1}$

An editorial ${ }^{2}$ puts into perspective two of the European studies. ${ }^{3,4}$ De Sutter and colleagues provide important evidence about the effectiveness of antibiotics. Van Driel and colleagues find that sore throat patients who ask for antibiotics are in fact looking for pain relief, a finding with direct implications for practice. These studies add to the growing literature on overuse of antibiotics for upper respiratory infections ${ }^{5-9}$ and are featured in the Annals Journal Club. ${ }^{10}$

An essay by Brody ${ }^{11}$ takes a close look at the science and ethics of BiDil, a controversial drug approved for use in African Americans. Although BiDil appears to offer benefit for some patients, Brody calls for a skeptical approach to prescribing, given the sociocultural context and commercial motivation surrounding the drug's development.

A Scottish study ${ }^{12}$ finds that, in contrast to the technical aspects of diagnosis and treatment that are the focus of most efforts to transform care, general practitioners' satisfaction with their work is more closely related to developing and maintaining relation- ships. As quality improvement interventions work to improve technical aspects of care, these findings can guide efforts to maintain or improve the morale of those who provide the care.

An elegant study from general practices in the Netherlands finds that complaints, particularly abdominal pain and headache, cluster in families, and especially in mothers and children. ${ }^{13}$

A well-designed epidemiological study examines the issue of breast cancers diagnosed within 1 year of a normal screening mammogram. ${ }^{14}$ One half of these cancers, which apparently were undetected by a widely used screening test, are discovered in women who seek health care for a breast complaint, and $17 \%$ are found by clinicians conducting a routine breast examination. A personal or family history of breast cancer or a lump most often drove the health care visit during which the cancer was discovered. This study is a reminder that our screening tests are not perfect, and that listening to patients' complaints, considering risk factors, and performing a careful examination remain important.

A qualitative study by McKee and colleagues ${ }^{15}$ discovers that while mothers have a low awareness of their adolescent daughters' sexual activity, they are strongly committed to protecting their daughters' reproductive outcomes. These findings should prompt reflection within families as well as in health care settings.

Karasz and colleagues ${ }^{16}$ find that Hispanic patients perceptions of the efficacy of depression treatment do not match priorities implicit in current treatment guidelines. These findings are a call for listening to patients, educating them about what works, and pursuing their perceptions of efficacy as hypotheses for developing and evaluating new, culturally specific interventions.

Two studies of influenza vaccines are relevant as the influenza flu season gets under way. Zimmerman 
and colleagues find that interventions tailored to the particular needs of inner-city health centers appear to modestly increase childhood influenza vaccination rates. ${ }^{17}$ Schade and Hannah ${ }^{18}$ document the effect of the severe 2004 influenza vaccine shortage in reducing vaccination rates, finding an interesting (and I suspect complex) relationship with continuity of care.

\section{GLOBAL THEME ISSUE}

This issue also includes a call for papers for a forthcoming theme issue highlighting problems of poverty and human development. The Annals is proud to participate in this international initiative, in which journals from both developed and developing countries will simultaneously publish papers related to this urgent global topic. Please consider submitting original research, methodology, theory, systematic reviews, or essays pertaining to poverty and human development. Manuscripts received before February 1, 2007, will have the best chance of being considered. For further information, see the call for papers in this issue, available at http://www.annfammed.org/misc/ PovertyCFP.shtml.

We encourage readers to share experiences and ideas by joining the Annals online discussion at http:// www.AnnFamMed.org.

\section{References}

1. Gulliford MC, Naithani S, Morgan M. Measuring continuity of care in diabetes mellitus: an experience-based measure. Ann Fam Med. 2006;4:548-555.

2. Hickner J. A new look at an old problem: inappropriate antibiotics for acute respiratory infections. Ann Fam Med. 2006;4:484-485.

3. De Sutter A, Lemiengre M, Van Maele G, et al. Predicting prognosis and effect of antibiotic treatment in rhinosinusitis. Ann Fam Med. 2006;4:486-493.
4. van Driel $M$, de Sutter $A$, Deveugele $M$, et al. Are sore throat patients who hope for antibiotics actually asking for pain relief? Ann Fam Med. 2006;4:494-499.

5. Gonzales R, Bartlett JG, Besser RE, et al. Principles of appropriate antibiotic use for treatment of acute respiratory tract infections in adults: background, specific aims, and methods. Ann Intern Med. 2001;134:479-486.

6. Gonzales R, Bartlett JG, Besser RE, et al. Principles of appropriate antibiotic use for treatment of nonspecific upper respiratory tract infections in adults: background. Ann Intern Med. 2001;134:490-494.

7. Hickner JM, Bartlett JG, Besser RE, et al. Principles of appropriate antibiotic use for acute rhinosinusitis in adults: background. Ann Intern Med. 2001;134:498-505.

8. Cooper RJ, Hoffman JR, Bartlett JG, et al. Principles of appropriate antibiotic use for acute pharyngitis in adults: background. Ann Intern Med. 2001;134:509-517.

9. Gonzales R, Bartlett JG, Besser RE, et al. Principles of appropriate antibiotic use for treatment of uncomplicated acute bronchitis: background. Ann Intern Med. 2001;134:521-529.

10. Stange, KC. Annals journal club: antibiotics for common respiratory infections. Ann Fam Med. 2006;4(6):iii.

11. Brody H, Hunt L. BiDil: Assessing a race-based pharmaceutical. Ann Fam Med. 2006;4:556-560.

12. Fairhurst K, May C. What general practitioners find satisfying in their work: implications for health care system reform. Ann Fam Med. 2006;4:500-505.

13. Cardol M, van den Bosch WJHM, Spreeuwenberg PP, Groenewegen $P$, van Dijk $L$, de Bakker D. All in the family: headaches and abdominal pain as indicators for consultation patterns in families. Ann Fam Med. 2006:4:506-511.

14. Carney PA, Steiner E, Goodrich ME, et al. Discovery of breast cancers within 1 year of a normal screening mammogram: how are they found? Ann Fam Med. 2006;4:512-518.

15. McKee MD, O'Sullivan LF, Weber CM. Perspectives on confidential care for adolescent girls. Ann Fam Med. 2006;4:519-526.

16. Karasz A, Watkins L. Conceptual models of treatment in depressed Hispanic patients. Ann Fam Med. 2006;4:527-533.

17. Zimmerman RK, Hoberman A, Nowalk MP, Lin C, et al. Improving influenza vaccination rates of high risk inner-city children over 2 intervention years. Ann Fam Med. 2006;4:534-540.

18. Schade CP, Hannah KL. Impact of the 2004 influenza vaccine shortage on repeat immunization rates. Ann Fam Med. 2006;4:541-547. 